\title{
Design of Mechanically Actuated Aerodynamic Braking System on a Formula Student Race Car
}

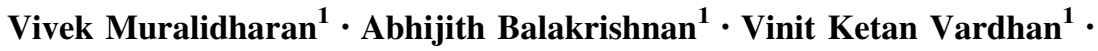 \\ Nikita Meena ${ }^{1} \cdot$ Y. Suresh Kumar ${ }^{1}$
}

Received: 20 March 2015/Accepted: 23 March 2017/Published online: 9 May 2017

(C) The Institution of Engineers (India) 2017

\begin{abstract}
Every second in a racing competition counts the performance of a team against the other. Many innovative and sophisticated techniques are being employed to overcome loses in time and add to the performance of the vehicle. Especially in a car racing challenge there is more freedom to install these innovative systems to empower the car to maximum efficiency due to availability of more space. At the global spectrum there are few events which encourage such innovations. Formula Student Racing competitions are one of the global events organized by the Society of Automotive Engineers of different countries which gives opportunity to university students to build and race formula style cars. Like any other racing competitions in this high octane event having an inch over their opponents is always an advantage. Not just better acceleration and high velocities but also good deceleration is required to excel in the competition. Aerodynamic braking system is utilizing the aerodynamic drag force to create high deceleration. This mechanism can be installed on any car with spoilers with minimum modification. Being a student event great amount of care needs to be given to the safety concerns of the driver.
\end{abstract}

Keywords Aerodynamic wings - Aerodynamic braking Airfoil · Downforce · Drag · Formula student racing

Vivek Muralidharan

vivek.nair.152@gmail.com

1 Department of Mechanical Engineering, National Institute of Technology Karnataka, Surathkal, Mangalore 575025, Karnataka, India

\section{Introduction}

The Society of Automotive Engineers (SAE) in different countries organize the formula student racing events governed by common rules and regulations set by SAE International. This event is tailor-made for the university students to design and build a formula style race car and compete with their peers. It gives liberty to the student teams to innovate mechanisms for better performance of the vehicle under certain terms and conditions. Being a student competition a lot of care has been given to safety of the students, thereby having strict rules on designing and manufacturing aspects of the car. Therefore any modifications on the car should abide by the stringent terms of the rules [1].

Like any racing event, a student racing event also has the thrill and intensity of competition. Minimal lap timings are the concern of all the participating teams. Along with good acceleration and high velocity, a good deceleration is an important parameter which decides the performance of the vehicle. A good amount of deceleration is required especially while maneuvering sharp corners [2]. Besides, the Formula Student racing event is classified into static events and dynamic events. In order to qualify to the dynamic events every team must clear the technical inspection which includes the brake test [3] wherein every car should brake in a straight line between two marked lines on the track. It can be accounted that better deceleration is required to execute smooth cornering and qualify the brake test. In order to increase the braking ability of the car, the drag created while steering can be utilized. The aerodynamic wings also known as the spoilers can be modified to capture the drag force created due to the motion of the vehicle and thereby contribute to braking. This paper is based on the work done over the NITK 
Racing Formula Student Car to capture the drag force by changing the angle of attack of the rear airfoil while braking. On application of brakes, the aerodynamic wings present at the rear are adjusted to corresponding angle of attack where the drag created is maximum. A study has been done to find the amount of braking force at different angle of attack at different velocities.

\section{Maximum Coefficient of Drag Condition}

The research $[4,5]$ infers that the coefficient of drag of any airfoil keeps increasing till angle of attack is $90^{\circ}$. In the same manner the rear wing for team NITK Racing as discussed [6] is optimized with a mechanism to alter the angle of attack of the top blade at the rear to cause more drag force while braking.

It is not always possible to achieve the maximum drag condition with the proposed mechanism due to the limited space for accommodating the movable links. As explained the flat plate theory [5] the coefficient of drag $\left(C_{D}\right)$ is a function of sine of the angle of attack $(\alpha)$ as in Eq. (1).

$\mathrm{C}_{\mathrm{D}}=2 \sin ^{2} \alpha$

where $\alpha$ can vary between $30^{\circ}$ and $80^{\circ}$. In such cases even before the airfoil is turned to $90^{\circ}$ it should provide sufficient drag force.

Based on Timmer's conclusion [5] maximum coefficient of drag can be approximated to a linear function of the leading edge thickness as in Eq. (2).

$\mathrm{C}_{\mathrm{D}, \max }=(1.994-5.4375) \mathrm{y} / \mathrm{c}$

where $\mathrm{y}$ is the airfoil thickness measured at the leading edge when $\mathrm{x} / \mathrm{c}$ is $0.0125, \mathrm{x}$ is the distance from the leading edge along the chord line and $\mathrm{c}$ is the chord length. For the Selig 1223 [7] airfoil the value of $y / c$ is 0.04846 . Hence the maximum possible theoretical coefficient of drag is 1.730 .

\section{Drag on Multiple Airfoil System}

\section{Coefficient of Drag of S1223 Airfoil}

The aerodynamic braking system at the rear comprises of two blade staggered arrangement. The bottom blade is stationary at a fixed inclination of $13^{\circ}$ at which maximum downforce is generated. This is connected the chassis for transmitting the aerodynamic forces generated. The top blade has the freedom to rotate about the pivot axis. The Selig 1223 is an unsymmetrical deep cambered airfoil, because of which the assumed aerodynamic center at $25 \%$ chord is located outside the airfoil cross-section. The pivot point is designed such that it lies within the airfoil cross section nearer to the aerodynamic center. The major reason for proximity of pivot point to the aerodynamic center is that the aerodynamic lift and drag force and moment are transferred to the structure effectively. Besides, not much strain is generated on the body of the blades due to minimum load transfer.

As explained [8] through Eq. (3) the net coefficient of drag is the sum of all coefficient of drags due to individual airfoils to that of the drag created due to interference of the two airfoils.

$\mathrm{C}_{\mathrm{D} 1,2}=\mathrm{C}_{\mathrm{D} 1}+\mathrm{C}_{\mathrm{D} 2}+\mathrm{C}_{\mathrm{D} \text { interference }}$

For orientation of top blade at $90^{\circ}$, the drag created is 1.730. At $13^{\circ}$ inclination the bottom blade produces $C_{D}$ of 0.045 . Therefore the staggered system must produce more than the sum of individual coefficient of drag as in Eq. (4)

$\mathrm{C}_{\mathrm{D} \text {, staggered wing }} \geq \mathrm{C}_{\mathrm{D} \text { top }}+\mathrm{C}_{\mathrm{D} \text { bottom }}$

The value of $C_{D}$, staggered wing thus obtained shall be greater than 1.775. For an ideal S1223 winged structure such high value of coefficient of drag could have been possible. Alterations to the design of the airfoil change the coefficient of drag significantly.

\section{Coefficient of Drag of Modified Airfoil Structure}

Due to the rule specification of Formula Student racing [1] it is mandatory to use a modified structure with $1.5 \mathrm{~mm}$ radius of curvature at the tail end therefore the sharp tail end needs to be shred as in Figs. 1, 2 Because of such modification in the airfoil profile, it does not generate the exact amount of drag force created by a normal S1223 airfoil.

The modified airfoil structure is not a standard structure hence CFD analysis is the primary method to calculate the value of coefficient of drag. The angle of attack of thetop blade is varied from the maximum lift condition of $13^{\circ}$ angle of attack as in Fig. 3 to sequential increase in angle of attack varying from $17^{\circ}, 25^{\circ}, 40^{\circ}, 60^{\circ}$ to finally $90^{\circ}$ as shown in Figs. 4, 5, 6, 7, 8, respectively.

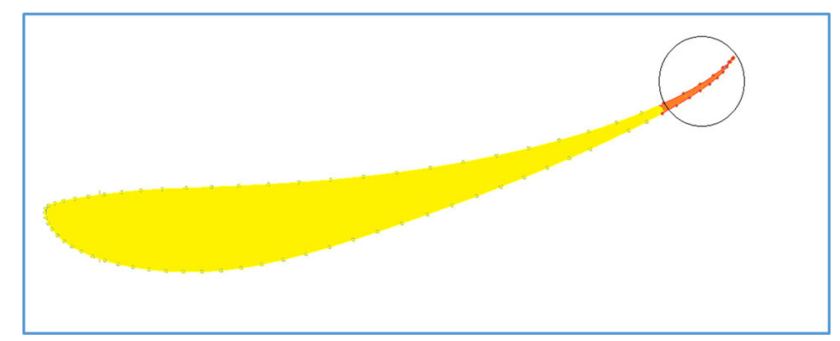

Fig. 1 Tail end (rear) up to the desired dimension [6] 


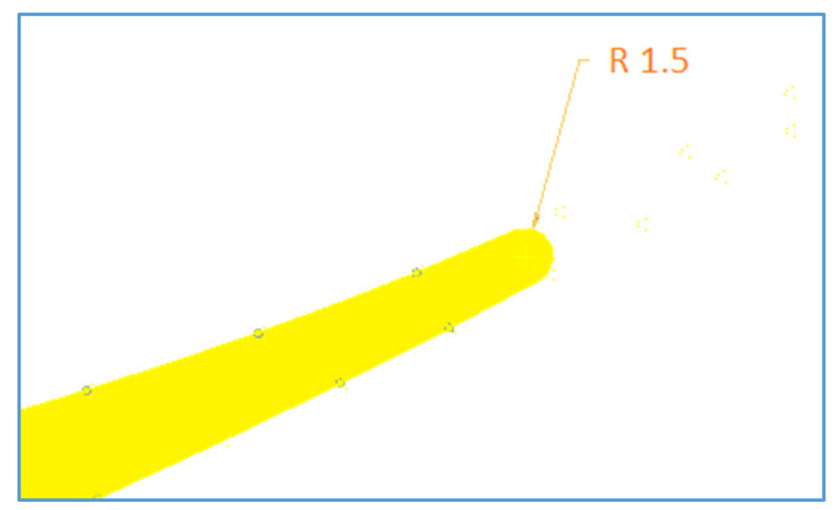

Fig. 2 Tail surface with chamfer of $1.5 \mathrm{~mm}$ radius [6]

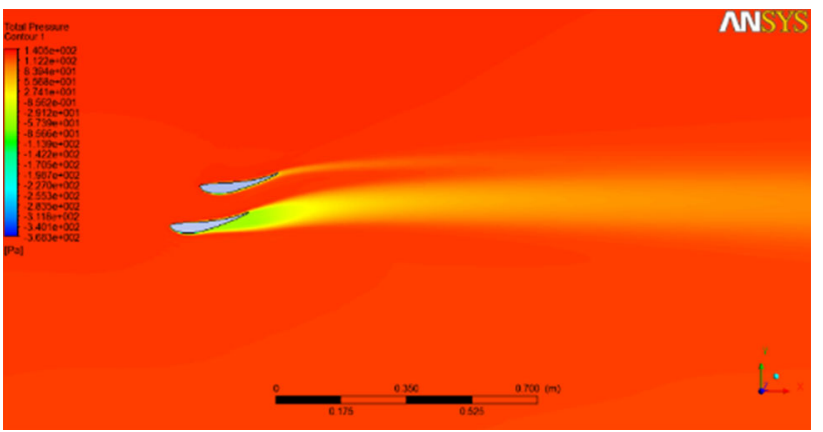

Fig. 3 Total pressure distribution $\left(\alpha=13^{\circ}\right)$

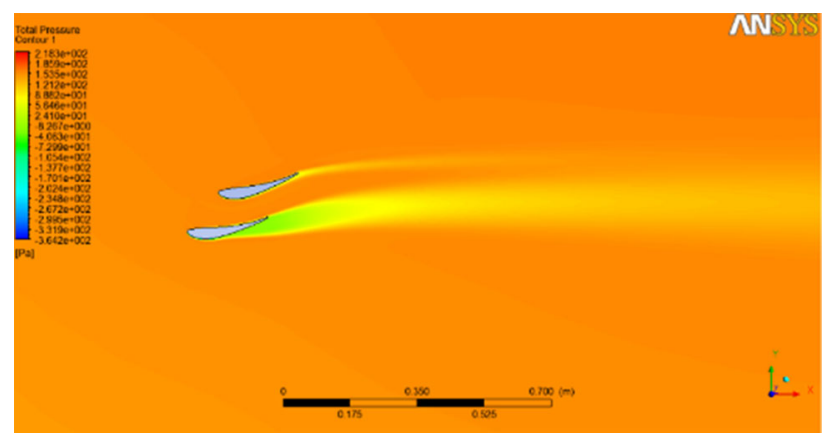

Fig. 4 Total pressure distribution $\left(\alpha=17^{\circ}\right)$

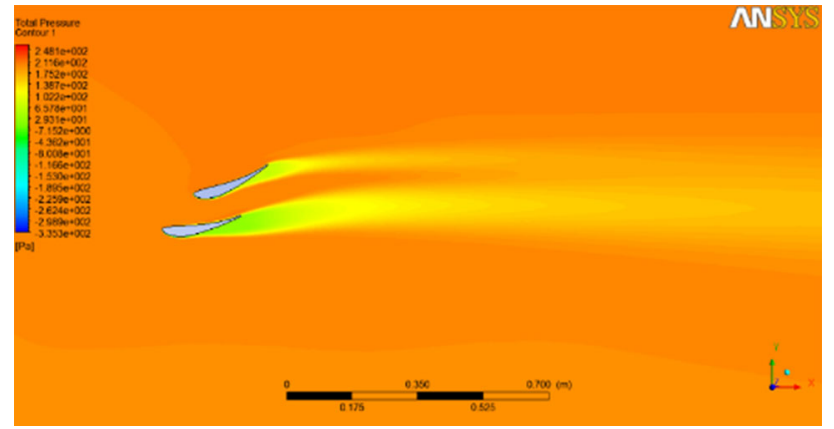

Fig. 5 Total pressure distribution $\left(\alpha=25^{\circ}\right)$

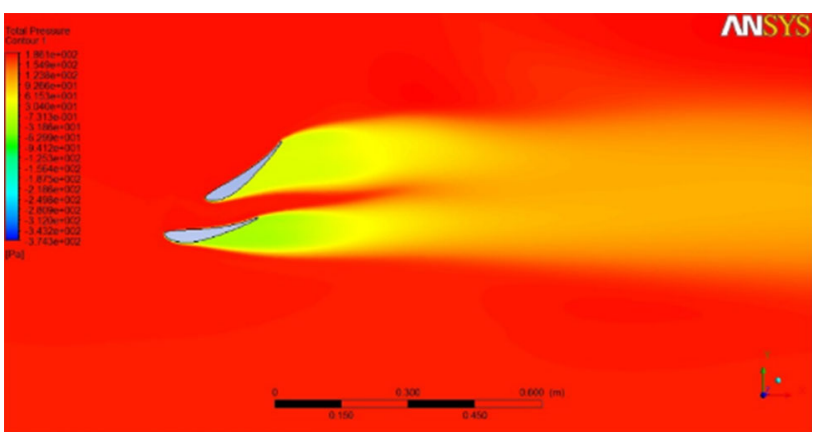

Fig. 6 Total pressure distribution $\left(\alpha=40^{\circ}\right)$

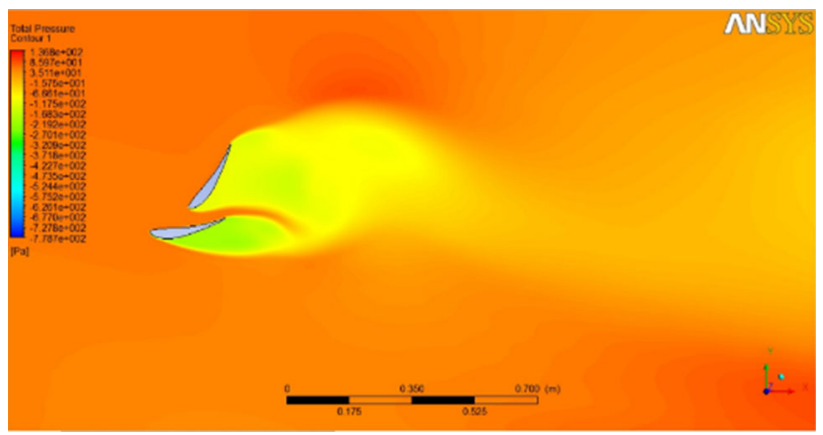

Fig. 7 Total pressure distribution $\left(\alpha=60^{\circ}\right)$

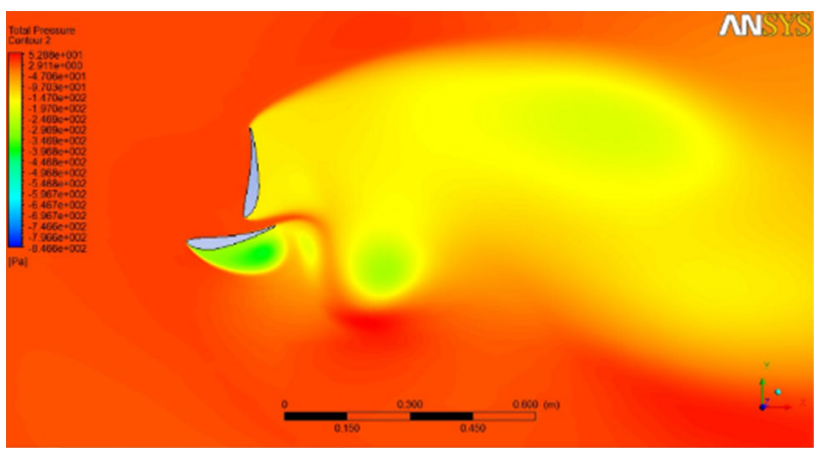

Fig. 8 Total pressure distribution $\left(\alpha=90^{\circ}\right)$

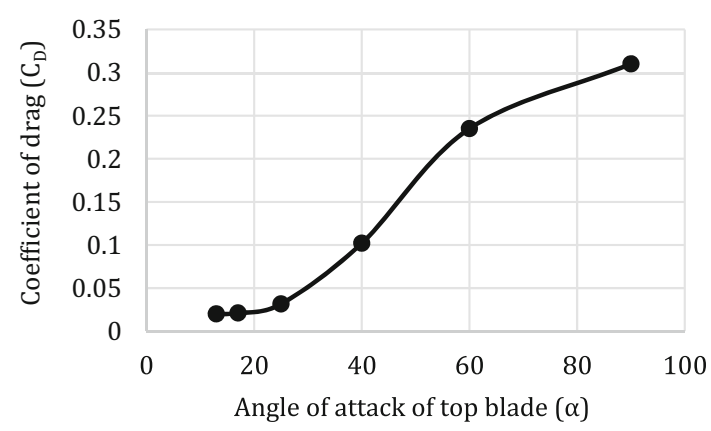

Fig. 9 Coefficient of drag against angle of attack 


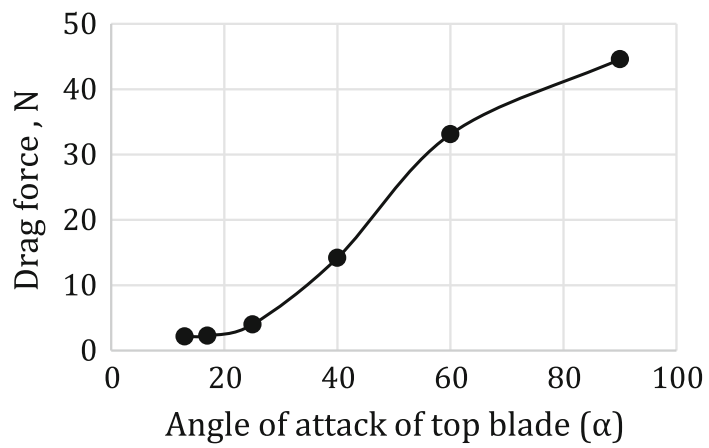

Fig. 10 Drag force against angle of attack at $50 \mathrm{kmph}$

For the modified Selig 1223 with shredded tail end, the coefficient of drag against angle of attack was calculated through the computational analysis as in Fig. 9.

As [9] the most frequently attained velocity of $50 \mathrm{kmph}$ is assumed as the base for calculating the flow characteristics and to solve the coefficient of drag in ANSYS Fluent. The values are then extrapolated for different velocities and different angles of attack through the drag equation as in Eq. (5)

Drag $=\frac{1}{2} C_{D} \rho A v^{2}$

At a particular velocity (v) at very low Mach number it can be assumed that the density of air $(\rho)$ does not change throughout. Therefore aerodynamic drag is directly proportional to the coefficient of $\operatorname{drag}\left(\mathrm{C}_{\mathrm{D}}\right)$ at that corresponding angle of attack and area of impact (A) as understood through Fig.10.

The coefficient of drag of the modified airfoil even at $90^{\circ}$ angle of attack is considerably lower than that of the maximum coefficient of drag of 1.775 predicted for the actual S1223 airfoil. The considerable difference in maximum coefficient of drag is due to the shredding of the tail end, which indeed contributes significantly to the lift and drag produced by any airfoil as explained [6]. Nevertheless for better breaking even the smallest addition to the brake performance is an advantage to the car.
For constant angle of attack of the top blade, the net area of impact and the coefficient of drag is constant. The drag force increases at the rate of square of its velocity. For the same aerodynamic system, the drag force generated at high velocities and higher angles of attack are substantially large. This can be inferred through the statistics available on drag force values for different velocities are plotted in Table 1.

The effectiveness of aerodynamic braking increases at higher velocities since the drag force at higher velocities are very large. According [10], to the average weight of a formula student car is about $230 \mathrm{~kg}$, hence complete braking at $110 \mathrm{kmph}$ with $215.81 \mathrm{~N}$ drag force will effectively produce a deceleration of about $0.94 \mathrm{~m} / \mathrm{s}^{2}$ that is about $0.096 \mathrm{G}$-force while the same will produce a deceleration of $0.19 \mathrm{~m} / \mathrm{s}^{2}$ or $0.02 \mathrm{G}$ when braking at $50 \mathrm{kmph}$.

From the statistics available from FS Austria 2009 [11], the average velocity achieved for the brake test is about $90 \mathrm{kmph}$. In order to qualify the brake test, all wheels of a car has to lock and stop within the $25 \mathrm{~m}$ range. When braking at the $90 \mathrm{kmph}$ velocity within $25 \mathrm{~m}$ range, the deceleration produced by it is about $12.5 \mathrm{~m} / \mathrm{s}^{2}$ or $1.27 \mathrm{G}$. The contribution that the aerodynamic package can make is about $144.47 \mathrm{~N}$ drag at this velocity, producing additional $0.628 \mathrm{~m} / \mathrm{s}^{2}$ deceleration which is $4.7 \%$ of total braking. Although the drag produced changes continuously when the car decelerates, but since the time period is very small it is assumed to be constant at the speed of braking. The effectiveness of this aerodynamic wings vary with velocity producing higher effectiveness when braking at higher velocities as the drag created increases drastically compared to the braking at wheels, nevertheless even smaller addition to the overall breaking can create a huge difference on the track.

\section{Mechanical Actuator Design}

The translational movement of the brake pedal needs to be converted into the rotational movement of the airfoil blade to increase drag while braking. This can be achieved by

Table 1 Drag force at different velocities at different angles of attack

\begin{tabular}{|c|c|c|c|c|c|c|c|c|}
\hline \multirow[t]{3}{*}{ Angle of attack, degree } & \multicolumn{8}{|c|}{ Drag force, $\mathrm{N}$} \\
\hline & \multicolumn{8}{|c|}{ Velocity, kmph } \\
\hline & 40 & 50 & 60 & 70 & 80 & 90 & 100 & 110 \\
\hline 13.00 & 1.38 & 2.15 & 3.10 & 4.22 & 5.51 & 6.97 & 8.61 & 10.42 \\
\hline 17.00 & 1.45 & 2.27 & 3.27 & 4.46 & 5.82 & 7.37 & 9.09 & 11.00 \\
\hline 25.00 & 2.55 & 3.99 & 5.75 & 7.82 & 10.22 & 12.93 & 15.96 & 19.32 \\
\hline 40.00 & 9.07 & 14.18 & 20.41 & 27.78 & 36.29 & 45.93 & 56.70 & 68.61 \\
\hline 60.00 & 21.18 & 33.10 & 47.66 & 64.88 & 84.74 & 107.25 & 132.40 & 160.21 \\
\hline 90.00 & 28.54 & 44.59 & 64.21 & 87.40 & 114.15 & 144.47 & 178.36 & 215.81 \\
\hline
\end{tabular}




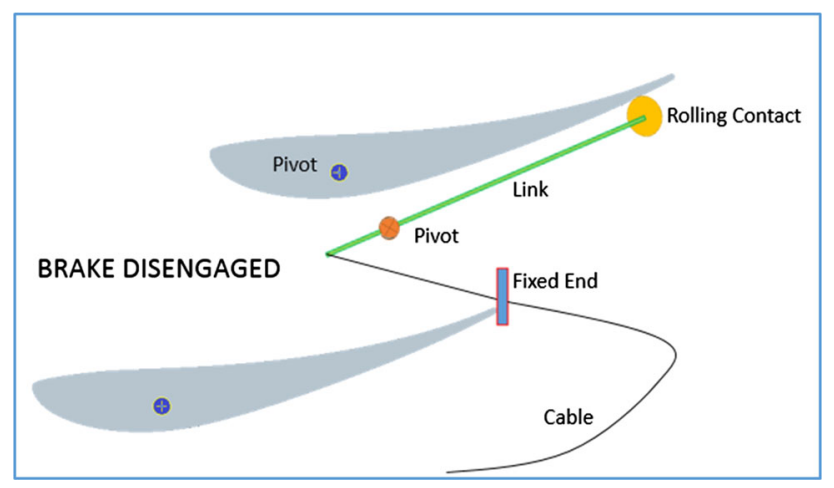

Fig. 11 Actuator position when brakes disengaged

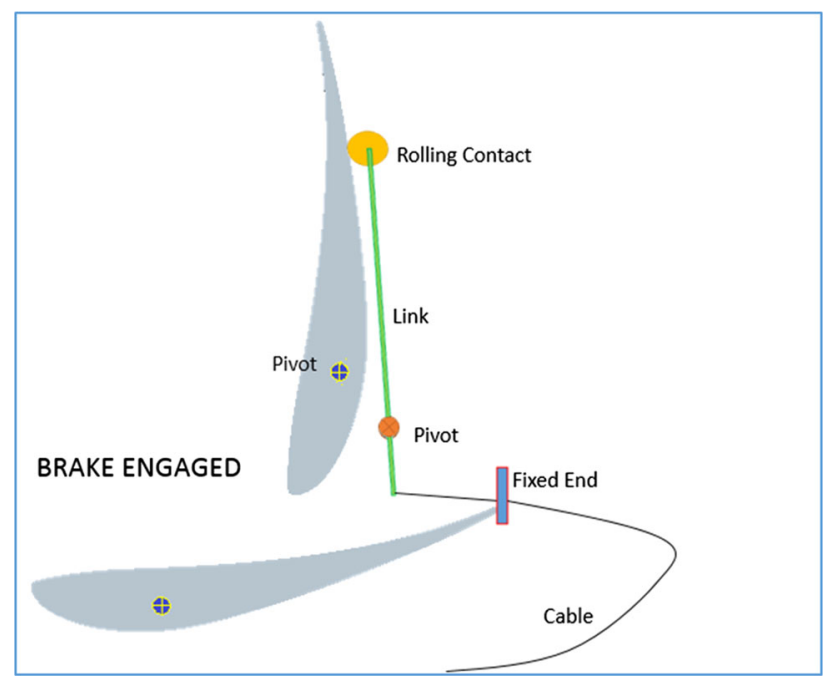

Fig. 12 Actuator position when brakes engaged

electronic means which can sense the pedal movement and use this as the input for the servo controlled motors which alter the angle of attack of the top blade [12]. The method however precise, is sophisticated. Program to run the servo needs to make the arrangements for the actuation of the blade, also a continuous power supply is needed to actuate. The mechanical method of actuation is much simpler and economic. It converts the brake pedal travel to the rotational motion at the hinge through tension cable.

The cable is attached to the fixed end as shown in Fig. 11, when the driver applies the brake, the brake pedal travel is transmitted by the cables to actuate the link through the fixed end. The roller forces the change in angle of attack of the top blade corresponding to the travel to reach a final braking state with maximum drag as described in Fig. 12. The link and the rolling contact together indeed acts as a cam mechanism for a shorter stroke as explained [13]. Instead of directly attaching the cable to the top blade provision has been made to make a secondary mechanism that actuates. The main purpose of this is that the load is transferred through a line contact than a point contact in direct attachment hence ensuring that the aerodynamic blades are not damaged during the actuation. It is always easier, economic and feasible to replace the other components than the wings. The pivot point on the link can be moved depending on the relation between input travel to the output rotation required. The length of the link on either side of the pivot point can be varied depending on torque requirements as well as alter the amount of rotation required.

As per observations from the NITK racing car, it is determined that the brake pedal has a $2.4 \mathrm{~cm}$ travel at the proposed mounting point. The upper wing is required to angularly displace by $77^{\circ}$ about its pivot corresponding to this travel. The cable transmits the same travel at the brake pedal to the point of attachment on the link. As per geometry, the point of attachment of the cable to the link from the pivot was calculated as $1.927 \mathrm{~cm}$. Allowing for cable play and other factors, a length of $2 \mathrm{~cm}$ from the pivot was finalized.

\section{Mechanical Actuator Setup}

The mechanical actuator is manufactured using nylon considering the force acting on it [14]. Most of the drag force is carried by the endplates of the aerodynamic wing along its hinge near to its aerodynamic center to the wheels. Considering only the remaining force which acts on the setup, nylon was chosen for its lightness and machinability [15]. The setup was mounted at the center of the bottom blade of the rear aerodynamic wing and high tension cable was connected between the brake setup and the brake pedal such that the brake travel can be transmitted till the setup. In case of any errors induced to the travel, the mounting point on the brake pedal may be suitably varied to account for the same. Stainless steel link is used to create play on the setup. Round rubber bob is placed on top of the link to create a rolling contact during its motion (Figs. 13, 14, 15, 16, 17).

\section{Scope for Future}

In this designed mechanism, the cable and the link are directly coupled hence it is a linear function of brake pedal travel to the rotation of the blade. Further analysis can be done to optimise the function of brake travel to the required output rotation. The function can be altered by changing the dimension and orientation of the secondary members that include the fixed end, link, pivot point and rolling contact. Besides multiple links and other components can 


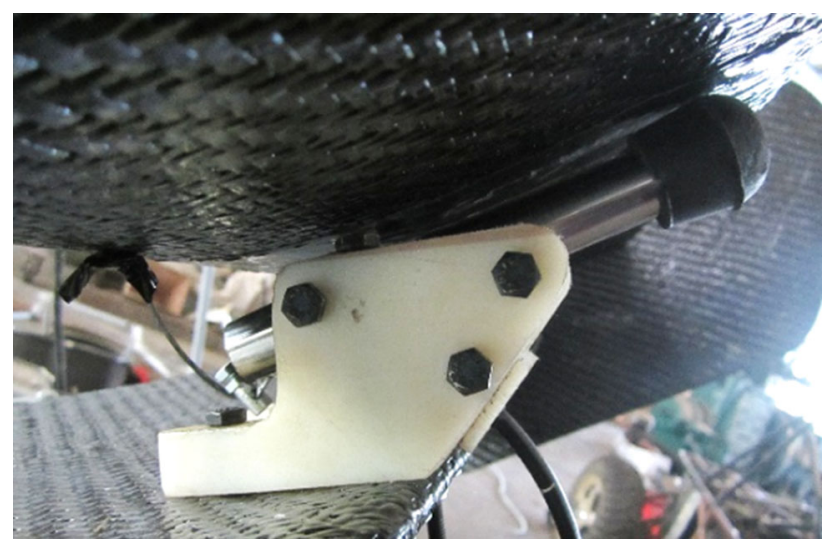

Fig. 13 Setup when brakes disengaged

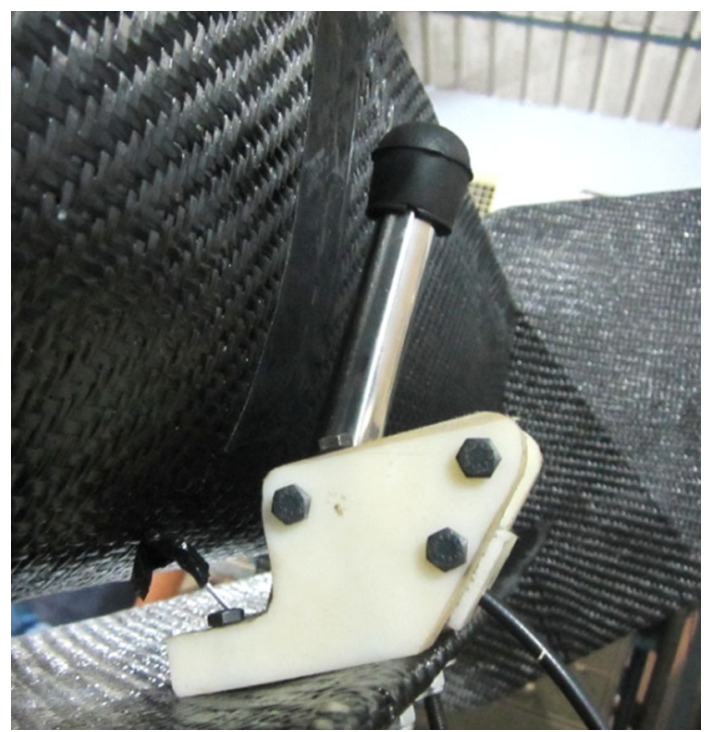

Fig. 14 Setup when brakes engaged

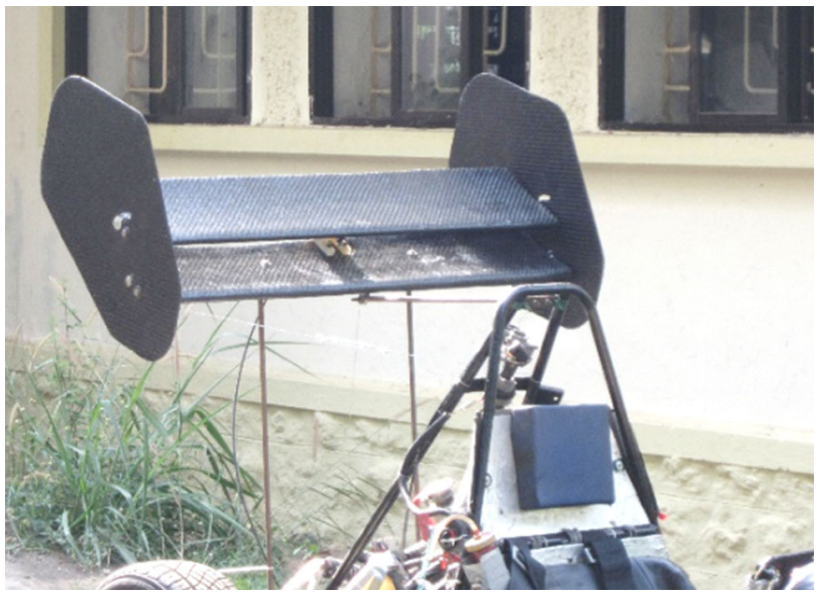

Fig. 15 Actual view of rear wings when brakes disengaged

be added to modify the existing relation between brake pedal travel and change in angle of attack of the blades.

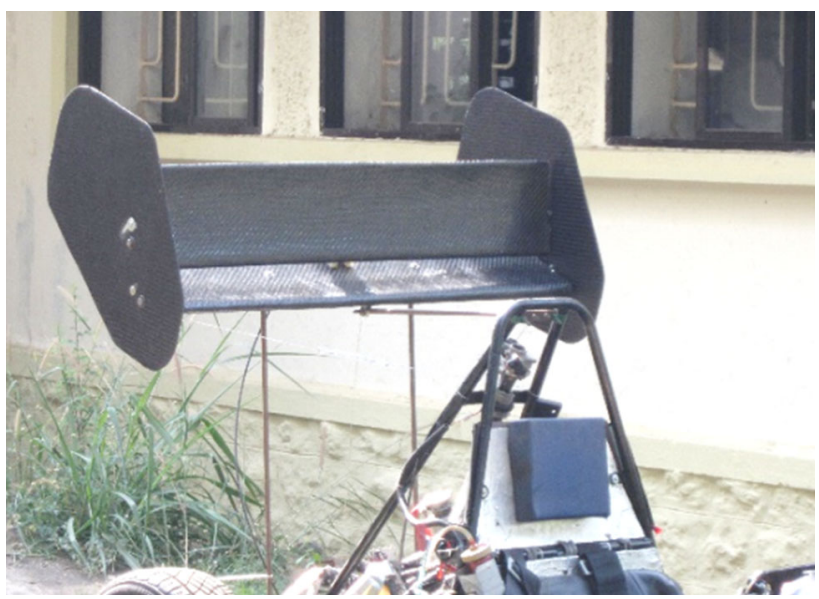

Fig. 16 Actual view of rear wings when brakes engaged

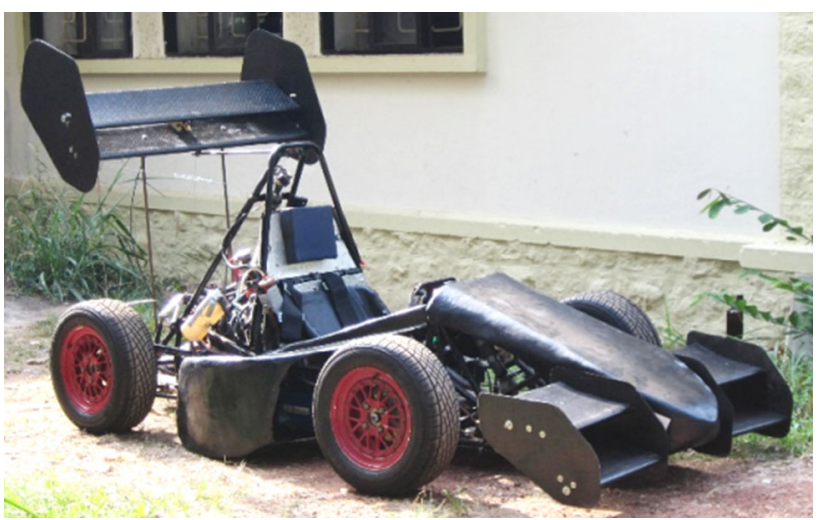

Fig. 17 Actual car with aerodynamic wings installed

Thorough experiments which include wind tunnel testing and on-track data acquisition, may be performed on the aerodynamic package to validate the results. Although not precise, driver feedback may be obtained from professional test drivers.

\section{Inference}

The drag force at various angles of attack at different velocities has been optimized for the modified S1223 airfoil. Moreover, a linear actuation mechanism is designed to transmit the brake pedal travel during braking to vary the angle of attack of the top rear aerodynamic blade to a maximum of $90^{\circ}$ angle of attack to achieve maximum braking.

Acknowledgements The authors are grateful to the faculty advisor of team NITK Racing for his immense support to the team throughout. Faculty and staff members of the Department of Mechanical Engineering at NITK Surathkal, India provided great support to the authors in technical and managerial assistance. Gratitude to the entire team of NITK racing for their assistance while manufacturing. The 
authors are thankful to fellow project mates for their worthy contribution to this project. Sincere thanks to software providers, ANSYS and CREO.

\section{References}

1. SAE International: Formula SAE Rules, http://students.sae.org/ cds/formulaseries/rules/2014_fsae_rules.pdf. Accessed 04 July 2014

2. B. Beckman, No bucks racing club: the physics of racing, part 5: introduction to the racing Linehttp://www.esbconsult.com.au/ ogden/locust/phors/phors05.htm (1991). Accessed 27 Feb 2015

3. Institution of Mechanical Engineers (IMechE), UK, Formula Student, The Challenge, http://events.imeche.org/formulastudent/about-us/thechallenge. Accessed 15 Aug 2014

4. J.L. Tangler, J.D. Kocurek, Wind turbine post-stall airfoil performance characteristics guidelines for blade-element momentum methods, 43rd AIAA Aerospace Sciences Meeting and Exhibit, 10-13, 2005

5. W.A. Timmer, Aerodynamic characteristics of wind turbine blade airfoils at high angles-of-attack. 3rd EWEA Conference-Torque (2010): The Science of making Torque from Wind, Heraklion, Crete, Greece, 28-30 June 2010. European Wind Energy Association, 2010

6. V. Muralidharan, A. Balakrishnan, S. Kumar, Design optimization of front and rear aerodynamic wings of a high performance race car with modified airfoil structure, ICNTE, IEEE (2015). doi:10.1109/ICNTE.2015.7029904

7. Airfoil Tools: Selig S1223 high lift low Reynolds number airfoil http://airfoiltools.com/airfoil/details?airfoil=s1223-il Accessed 14 Aug 2014

8. Pilotfriend, Fixed wing flight training: aerodynamics of drag, http://www.pilotfriend.com/training/flight_training/aero/drag.htm (2008). Accessed 13 Jan 2015

9. S. Wordley, S. Saunders, Aerodynamics for formula SAE: initial design and performance prediction, SAE Technical Paper Series, 2006-01-0806, SAE International, 2005

10. Formula Society of Automotive Engineers, http://en. wikipedia.org/wiki/Formula_SAE (2015). Accessed 18 Jan 2015

11. Braking Performance at Formula Student Competition, http://www.fsae.com/forums/showthread.php?894-Average-1000-kph-braking-performance (2009). Accessed 25 Sept 2014

12. N. Balakrishnan, M. Alnouri, M. Heiranian, W. Koos, Design of a front aerodynamic package, University of Manitoba, Canada unpublished (2011)

13. Y. Zhang, S. Finger, S. Behrens, Introduction to Mechanisms, Rapid Design through Virtual and Physical Prototyping, https://www.cs.cmu.edu/ rapidproto/mechanisms/chpt6.html, 2010. Accessed 2 Nov 2015

14. M.W. Hyer, Stress Analysis of Fiber-Reinforced Composite Materials, vol. 32 (DEStech Publications Inc, 2009)

15. PEP connecticut plastics: basics of plastic selection for machining, http://www.pepctplastics.com/resources/plastic-part-design-guide/ basics-of-plastic-selection-for-machining/. Accessed 6 May 2015 